\title{
Summary.
}

It may be concluded from the preceding experiments:

I. That by means of a refusion with carbonate all the fluorine in silicate minerals can be accounted for by the Berzelius-Rose method.

2. That the conditions have been indicated according to which the best results can be obtained in the volatilization of silicon tetrafluoride by the Offermann method. This method is to be preferred for the direct estimation of fluorine in fluorspar.

3. That the soluble fluorides can be most accurately determined by precipitation as lead chlorofluoride.

4. That the only satisfactory method of determining and detecting fluorine in small quantities in minerals is the colorimetric method of Steiger-Merwin.

University of Pennsyluania.

[FROM THE DEPARTMENT OF CHEMISTRY OF THE UNIVERSITY OF ILIINOIS.]

\section{AN ACID-RESISTING ALLOY TO REPLACE PLATINOM IN THE CONSTRUCTION OF A BOMB CALORIMETER.}

\author{
BY S. W. PARR.
}

Received July 26, 1915.

In the construction of an oxygen bomb for calorimetric purposes the necessity of providing an interior surface, such as is afforded by a platinum lining, is a recognized essential under all circumstances, but especially important in the combustion of Illinois and related coals, where the nitrogen and sulfur result in the formation of a mixture of nitric and sulfuric acids, equivalent on the average to about $30 \mathrm{cc}$. of $0.05 \mathrm{~N}$ nitric acid. If a solvent action with the metal of the bomb occurs, the error is twofold, in that a too low correction for the total acid is indicated, thus increasing the heat credited to the fuel, and besides, any heat of solution developed by such action goes as a false credit to the fuel also and cannot be corrected for. The conditions as thus outlined would very naturally suggest the desirability of devising a metal or a complex which should be as resistant to the action of acids as platinum.

In arranging a working program where so little of the underlying principles have been developed, about the only method of procedure is the purely empirical one of trying many things. If we look for suggestions toward the theories proposed for the passivity of metals, we are impressed with the fact that investigators in that field are far from agreed as to what causes passivity. At best, however, passivity is only a transient condition and would seem not to be applicable to the problem in hand.

Another possible basis of procedure was formulated from reasoning somewhat after this fashion. There are many combinations of metals and metalloids having solubility characteristics quite different from the 
metals which enter into the compound. Or perbaps, to put it differently, we have a much wider range of insoluble substances among compounds of metals with nonmetals than among metals themselves. For example, in Family VI of the Periodic Table we have oxygen, sulfur, selenium, tellurium. Now among the metallic oxides we have some extremely insoluble compounds as silicon dioxide, aluminium oxide, tin oxide, etc. But these compounds are brittle, or have no metallic properties which fit them for use where toughness or malleability are essential.

Take another combination. In Family IV we have silicon, more metallic in its properties than oxygen. If we combine silicon with iron up to say $17 \%$ of silicon, we have a silicide of iron, which is noted for its resistivity to solvents. While it melts and casts readily and has many applications in the arts, it is an extremely brittle substance and of such a very high degree of hardness that machining is impossible.

In the more metallic subdivision of Family VI we have chromium, molybdenum and tungsten, elements which have many nonmetallic properties and combine with oxygen to form acid radicals for many salts. They have also distinctively metallic properties, most pronounced so far as ductility is concerned in the case of tungsten, less so with chromium. If now we select certain metals which are notable in such characteristics as toughness and malleability, and which are at the same time in themselves somewhat resistant to acids, we might find some combinations which would retain or accentuate the insoluble feature of both constituents and have also a sufficient amount of toughness for working with machine tools. The metals which would naturally suggest themselves in this connection would be nickel, cobalt and possibly iron.

One further point may be noted. If we arrange the elements in an electrochemical series, and consider hydrogen as the dividing line between the electronegative and the electropositive substances, we shall find situated about midway between oxygen at the extreme electronegative end and hydrogen these four elements, chromium, vanadium, molybdenum, tungsten. Similarly, if we proceed from hydrogen towards the extreme electropositive end, we shall find about midway the elements cobalt, nickel, iron. Now we might attempt to satisfy the ionization viewpoint by reasoning in this fashion; here is an electronegative group, chromium, molybdentum, etc., which may be made to enter into combinations with certain members of the electropositive group in such a way as to neutralize or lower the ionization tendency of the metal to the vanishing point.

However hypothetical, or better perhaps however vague this line of reasoning, it served as a starting point. The first studies, therefore, were made on a nickel chrome series in which the chromium varied from $5-20 \%$, the remainder being nickel. Solubility tests were very encour- 
aging throughout the series, but there was a marked increase of resistivity with the higher percentage of chromium, that is, the $80 \mathrm{Ni}$ and 20 $\mathrm{Cr}$ series. An attempt was made to produce a casting using this proportion. The difficulties encountered were serious and have constituted the most troublesome feature to master, aside fiom the development of the actual composition of the alloy. Three characteristics were especially in evidence at this point: first, the high melting point of the mixture; second, the unusual amount of shrinkage at the moment of solidifying; and third, the coarsely crystalline texture of the metal. The attempt to pour the $80^{-20}$ member of the series into a molded form resulted in the production of a casting which, in places, had more the property of a sieve than of a solid metal.

A series was next devised in which it was sought to introduce a third metal which might lowe ${ }^{-}$the melting point without decreasing the resistivity of the mixture. Copper was selected for this purpose chiefly because of its relatively low melting point. It is readily soluble in nitric acid, however, and it was considered probable that it would lower the resistivity of the series. Up to a certain point, however, the opposite proved to be true. The copper was made to vary in amount from $5-30 \%$. The action of the acid was less evident up to a maximum of about $10 \%$.

This is a point of fundamental importance and furnished a decided argument for a study in detail of the ternary series thus represented. This is now being carried on and cannot be dwelt upon here. Encouraged by the experience with copper, two more metals were tried out, such as might be used to advantage in the molten bath to clear it of dissolved gases and thus reduce the flaws in the cast metal. In this way the limit for aluminium and manganese, separately or together, was found to be about $2 \%$.

Notwithstanding the progress that would seem thus to have been made in the direction of lowering the melting point, the metal was still coarse-grained in its fracture and seemingly could not be cast into usable forms. The fracture is shown in No. 7 of Fig. I. The charge for the melt consisted of $\mathrm{Ni}=75 \%, \mathrm{Cr}=20 \%, \mathrm{Cu}=5 \%$.

However, the honey-comb feature frequently in evidence in the earlier castings had given way to a better texture, but there were still minute

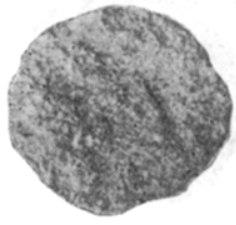

No. 7 .

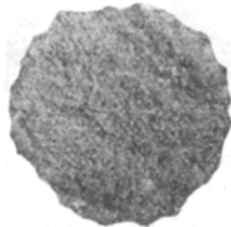

No. 14 .

Fig. I.

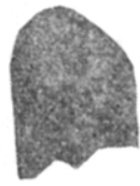

No. 21 . 
openings or pin-holes which would prevent the use of the metal in a high pressure gas container.

The next modification which produced any noticeable improvement was secured by use of a formula as follows:

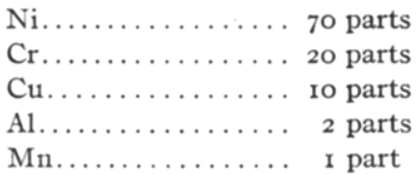

The close-grained character of the metal is shown in the fracture of No. I4, Fig. I. While the pin-holes were in evidence when a casting of this composition in the form of a bomb was put under 30 atmospheres pressure, still the extent of the porosity was sufficiently reduced to afford encouragement for continuing the experiments.

In devising the next series the experience so far seemed to indicate that the further addition of some metal might result advantageously, but this time it was decided to go to the electronegative side and take a near relative of chromium. In test No. $2 \mathrm{I}$, therefore, there was added four parts of metallic tungsten. The effect of this addition was noticeable at once in the fracture of the metal which was now very fine-grained instead of coarse, No. 2I, Fig. I, and for the first time a serviceable casting free from pin-holes was produced. It was small and of simple form, being intended as a cover for an old platinum lined bomb. As thus put into use it proved to be exceedingly satisfactory.

Test No. 23 was cast in similar form and mixture, and proved to be free from pin-holes. Moreover, the resistivity to acid action was the best so far obtained. In the accompanying microphotographs the change in the texture of the metal is shown by comparing test No. 8 with No.

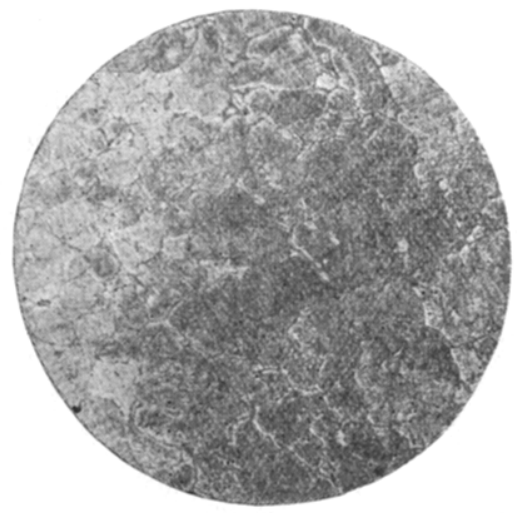

No. 8. Etched 3 min. in ${ }_{1} \% \mathrm{FeCl}_{3}$ in I : $\mathrm{I} \mathrm{HCl} \times 6$ o.

Fig. 2.

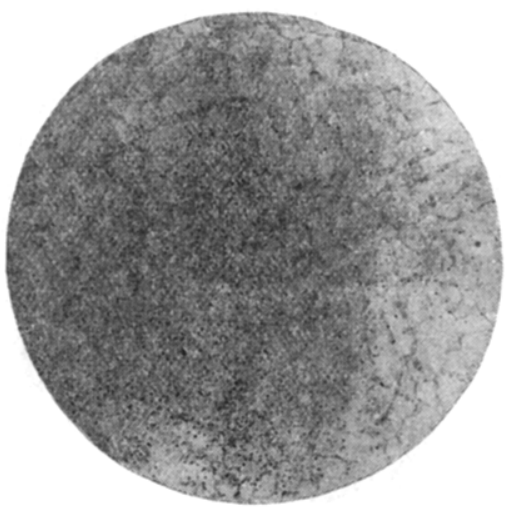

No. 23. Etched $\mathrm{I}$ min. in $\mathrm{I} \% \mathrm{FeCl}_{3}$ in I : $\mathrm{I} \mathrm{HCl} \times 60$ :

Fig. 3. 
23. In No. 8, Fig. 2, the composition was the same as that used in test No. 7 of Fig. I, while in No. 23, Fig. 3, the composition was the same as that used in No. 21 , Fig. 1.

A much more difficult problem still remained so far as casting the metal was concerned in attempting to produce the main body of the bomb, about 5 kilos in weight, in perfectly homogeneous form. This was secured in test No. 40, and the finished bomb was put into commission about February, 1912, since which time it has served in more than I 500 combustions, without evidence of corrosion. Many of the determinations were made parallel with the platinum-lined bomb and the results show conclusively that in actual service the alloy bomb gives results equivalent in every respect to those indicated by the platinum lined outfit. In Table I are shown the acid titration values as obtained from the two instruments at such times as they were run parallel during the years 1912 to 1914 , inclusive. For convenience the new alloy is referred to as "Illium." It will be seen that in 3 I determinations the illium bomb titrations were in excess. In 15 cases the platinum outfit gave the higher titrations. In no case, however, is the acid value from the illium bomb sufficiently low to indicate a solubility effect. Indeed the variations are only such as might normally occur in the use of the same apparatus.

Table I.-Acid Titration Values (in Cc. of Standard Alkali) Illustrating Resistivity OF aN ILLIUM ALIOY BoMB (I) CoMparED wITH THAT OF PLATINUM-LINED Bomb (PT).

\begin{tabular}{|c|c|c|c|c|c|c|c|c|c|c|c|c|}
\hline I $\ldots \ldots$ & 86.3 & 37.2 & 39.2 & 49.6 & 39.9 & 59.5 & 32.8 & 46.6 & 65.7 & 65.7 & 47.8 & 43.6 \\
\hline Pt. . & 76.2 & 41.5 & 42.9 & 5 I. 6 & $4 \mathrm{I} .4$ & 55.8 & $3 x .7$ & 44.7 & 59.0 & $43 . x$ & 39.9 & 38.2 \\
\hline & 20.6 & 40.6 & 39.4 & 44.0 & 46.0 & 41.9 & 40.9 & 31,8 & 41.6 & 44.4 & $4 \mathrm{I}, 2$ & \\
\hline & $22 . I$ & 36.7 & 36.5 & 40.1 & 41.5 & 38.0 & 42.7 & 30.5 & 39.7 & 37.0 & 45.4 & \\
\hline I. . & 26.3 & $45 \cdot 5$ & 46.4 & 29.4 & 39.0 & $4 \mathrm{I} .2$ & 40.6 & 40.5 & 3 I. 5 & 44.0 & 40.6 & \\
\hline $\mathrm{Pt}$ & 20.9 & 38.5 & 44.5 & 29.8 & 38.0 & 42.5 & 36.4 & 35.5 & 37.0 & $40, I$ & 36.7 & \\
\hline & 43.9 & 42 I & 38.2 & 46.0 & 29.4 & 23.2 & I 6.6 & 20.4 & 15.4 & 20.8 & 21.6 & \\
\hline Pt. & $4^{2} .4$ & 37.2 & 36.4 & $41 \cdot 5$ & 29.8 & 24.9 & I5.5 & 20.0 & 18.4 & 21.6 & 22.8 & \\
\hline
\end{tabular}

The pioperties of the metal are further indicated by the accompanying illustrations. Fig. 4 shows the cover made from test No. 23. This cover has been used on the bomb shown in Fig. 5 made from test No. 40. Fig. 6 , showing the lathe chips, affords a good illustration of the working properties of the metal.

The method adopted for measuring the action of acids was as follows: Test pieces were prepared having as nearly as possible a superficial area of Io sq. cm. The strength of acid employed was $4 N$ nitric and the loss of weight was determined after a submergence in the acid for 24 hours. Calculations were then made of the loss in weight per hour for 
a surface of $100 \mathrm{sq} . \mathrm{cm}$. On this basis test piece No. 23 gave a loss of $0.03 \mathrm{mg}$. This degree of resistivity has been easily maintained in subsequent work and indeed improved upon. Standard pieces for corrosion tests gave results from six out of the last seven melts in which there was no weighable loss after 24 hours' contact with $25 \%$ nitric acid.

Some idea of the difficulty attending the casting of this material may be inferred from the fact that the first perfect casting, No. 40, was obtained in December, $191 \mathrm{I}$. The next perfect result was No. 96 and was obtained about May I, I9I3, and not until over two years from this latter date did it seem possible to obtain perfect castings at will.

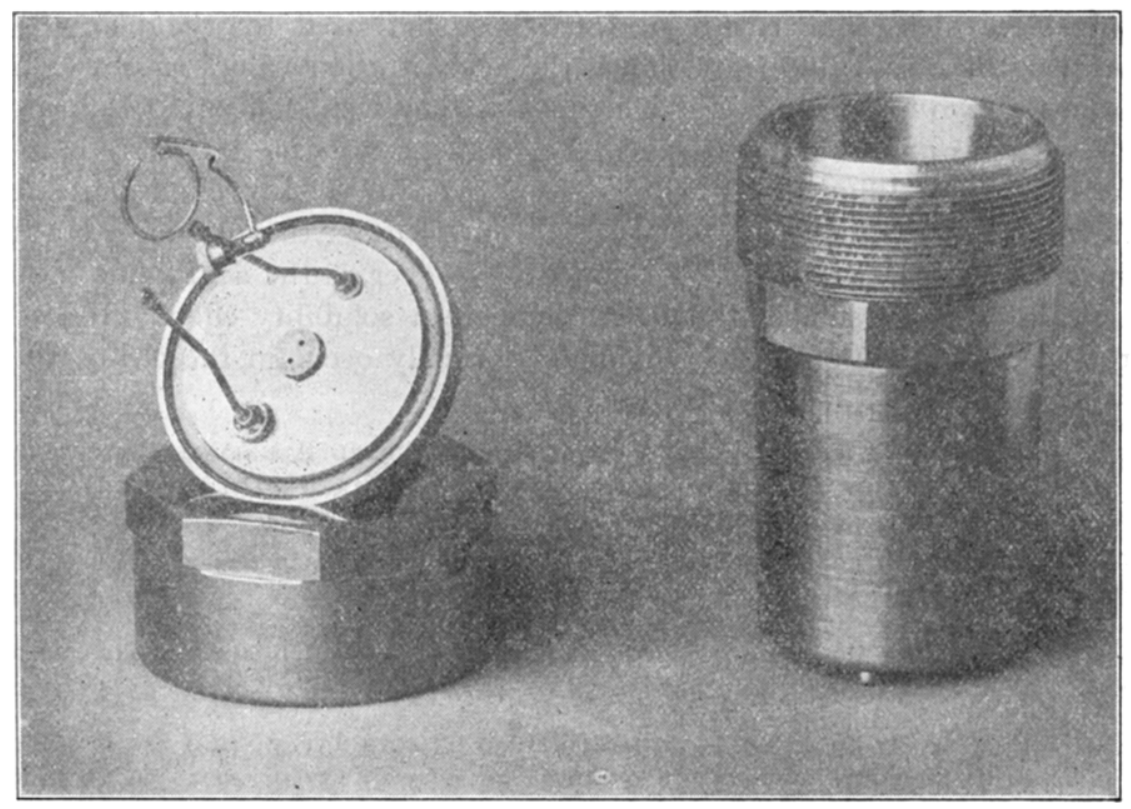

Fig. 4.

Fig. 5.

Not a little help in solving these difficulties has come from further experiments in varying the composition of the alloy. One other member of the chromium family has been added to advantage; name!y, molybdenum. It may be used up to $6 \%$ of the mixture either with or without the tungsten. It increases the resistivity to acids but lessens slightly the toughness and tensile strength. The metal is more dense and less liable to flaws of the pin-hole type. With tungsten and no molybdenum present the metal draws easily into wire, having a tensile strength of 124,000 pounds per square inch. In cast form the tensile strength, using tungsten in the mixture, is from 55,000 to 60,000 pounds per square inch. Where 
molybdenum is used, the tensile strength is from 50,000 to 55,000 pounds per square inch.

A temperature of approximately $1600^{\circ}$ is necessary to secure a perfect melt. As might be expected, the dissolved gases are troublesome and

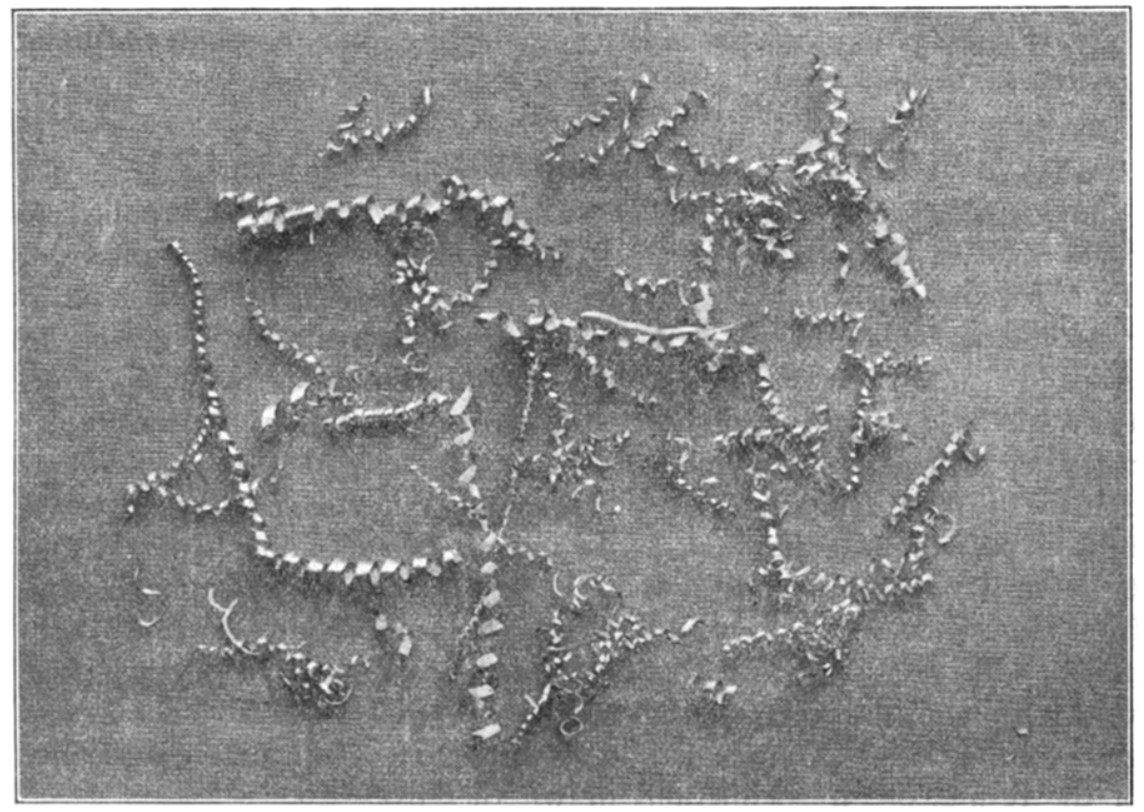

Fig. 6.

must be thoroughly removed before pouring. For this purpose from I to 2 parts of silicon-copper, manganese-titanium, and aluminium are added,"stirring the mixture well with a rod of pure nickel. A small amount of cryolite and boron suboxide are also added as a flux. On account of the high temperature employed graphite crucibles are necessary, but MeLT No. II 7 .

Percentage Composition of Illium Alloy. Analytical Results by F. E. Rowland and S. A. Braley.

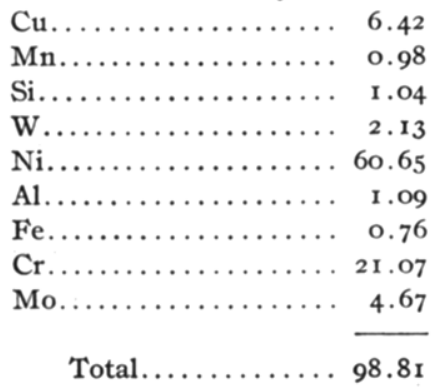


they must have a lining of silicious material, owing to the readiness with which carbon is absorbed by the molten material.

The analysis of the product requires a special study of methods. This has been carried out with fairly satisfactory results. The composition of a representative sample was found as shown in the preceding table.

No determination thus far has been made for carbon, boron or titanium.

URBANA, ILLINOIS.

\section{A CORRECTION.}

In an article entitled, "Can the Dissociation Theory be Applied to Solid Solutions in Steels?" which appeared in the September number of THIS JOURNAL, the specific resistances of the steel which had been hardened and subsequently reheated to different temperatures were given. In order to render the values as near the absolute value as possible corrections to the observed values necessitated through the calibrations of the recording instruments were made. The corrections expressed in microhms due to the high reading of the ammeter used amount in the present case to from 0.21 to 0.24 microhms, according to the specific resistance. As the ammeter read too high these corrections should have been subtracted from the observed values, but by mistake the corrections were in all cases added. In order, therefore, to reduce the values reported to their true value, from 0.42 to 0.48 microhms should be subtracted from the figures given in the table. This correction would in no way affect the significance of the results or any deductions drawn therefrom.

E. D. Campbell.

[Contributions from the Chemical Laboratory of Harvard UNIVizisity.]

HEXABROMODIACETYL.

BY C. LORING JACKSON AND ROGHR ADAMS.

Received August 28, 1915.

In an earlier paper ${ }^{1}$ A. H. Fiske and one of us described two acids, one melting at $207^{\circ}$, the other at $174^{\circ}$, made by the action of sodium hydroxide on tetrabromo-o-quinone, and it was also stated that, when treated with bromine and water, these acids were converted into a yellow diketone, to which the formula $\mathrm{CBr}_{3} \mathrm{CHBrCOCOCBr}$ was assigned. On continuing the study of this compound we have found that this formula is not the true one, but that it is really the hexabromodiacetyl $\mathrm{CBr}_{3} \mathrm{COCO}$ $\mathrm{CBr}_{3}$. The data on which this conclusion rests are given in Table I containing all the analytical results obtained by us from the substance itself and its principal derivatives. The first column gives the percentages calculated for $\mathrm{CBr}_{3} \mathrm{CHBrCOCOCBr}$, the second the data obtained by

1 Am. Chem. J., 50, 341 (1913). 